\title{
Riccardo Flamini and Pietro Traldi (Eds): Mass Spectrometry in Grape and Wine Chemistry
}

\author{
Peter Myers
}

Published online: 6 March 2011

(C) Springer-Verlag 2011



Some times I ask the question 'Is it worthwhile writing book reviews?' as I wonder if anyone reads them. Well in this particular case I am pleased to have read the book and write the review and I really do hope someone reads it and takes my advice in purchasing this excellent book.

Today the market is saturated with scientific books. Just do a search on the Web of Knowledge for science books and your search will terminate after 12,000 hits. Maybe not surprising as someone once told me that even as scientists we all have one book ready to publish. However, these authors have found what I believe to be a market gap and in doing so have produced a book that can be read by a very wide scientific audience. First of all it is very easy to read; I have found in the past that authors whose native tongue is not English can write in a very easy-to-read style. The book gives one of the best introductions to mass spectrometry that I have ever read. It provides great detail, e.g. complete analytical methods for the analysis of wine, but at the same time it is written in such a way that you can read these methods, understand the chemistry of the wine, the problems associated with the wines and the effect they have on the wine. I have been interested in corked wine for many years that results, in particular, from the presence of trichloroanisole and tribromoanisole. This book, along with many other problems, tackles the subject and deals with TCA in a clear and understandable way casting away many of the myths associated with corked wine.

This book is the third in the series, the other two being "Wine and Wine Making Analysis" and "Wine and Wine Making Chemistry". I would recommend you obtain the full series. But even if you just take this book you will gain so much knowledge that I am certain you will be the star at you next dinner party or wine tasting event or even in your local pub, when you explain about the non-anthocyanic polyphenols of the grape.

Is there a problem with the book? Yes, like many others the index, covering just two pages, is next to useless. But that is in using the book as a reference; to just read the book then of course you do not need the index.

So in summary, an excellent book is edited very well by Riccardo Flamini and Pietro Traldi and written by real experts in the field of mass spectrometry and wine chemistry.

P. Myers $(\bowtie)$

Department of Chemistry, University of Liverpool,

Liverpool L69 3BX, UK

e-mail: Peter.Myers@liverpool.ac.uk 